\title{
Improving Academic Performance Through Blended Learning: The Case of Afghan Higher Education
}

\author{
https://doi.org/10.3991/ijet.v16i11.20757 \\ Hamidullah Sokout ${ }^{(\bowtie)}$ \\ Kumamoto University, Kumamoto, Japan \\ Faculty of Computer Science, Kabul Polytechnic University, Kabul \\ h. sokoutekpu.edu.af \\ Tsuyoshi Usagawa \\ Kumamoto University, Kumamoto, Japan
}

\begin{abstract}
The last two decades have witnessed a global revolution in educational information that has led to the development and promotion of elearning. Blended Learning (BL) is an increasingly growing e-learning model with a background in pedagogical and psychological theory that combines both online and traditional activities. In recent years, it has been an emerging trend and has impacted the growth, revenue, learner retention, and academic accreditation in higher education. With current improvements, extensive research, and successful implementation of blended and fully online learning, little research has been done to report the success of transitioning from face-to-face to blended learning or evaluations of e-learning data regarding learners from developing nations, particularly Afghanistan. This study aims to investigate and analyze the effectiveness of educational types (blended vs. traditional) regarding learners' academic performance, in-class engagement, and satisfaction from the data in six BL courses and four traditional learning (TL) courses. To measure the success, this study used descriptive statistics. Additionally, Welch's $t$-test was used to compare BL with TL courses and assess the differences between success and failure levels for both courses. Likewise, the Pearson correlation coefficient, along with an ordinary least square regression, was used to indicate the relationship between the final score and the BL and TL activities, respectively. The study outcome will be used for reporting and feedback for educational parties to value the quality of teaching and learning, enhance learners' performances, and for the institutionalization of BL in the country.
\end{abstract}

Keywords - E-learning, Blended Learning, Descriptive Statistics, Teaching, Learning

\section{Introduction}

In the current century, most of the educational environments transitioned their teaching and learning from the traditional way to modern (e-learning) systems. The conventional method of teaching and learning has a predefined structure for all learn- 
ers, which does not support specified directions to meet individual needs and requirements [1]. In addition, due to a large number of learners and the possibility of diverse situations such as a heterogeneous group of learners who have different backgrounds from their professions, speak different languages, and have diverse skills and knowledge, traditional systems are too strict to provide the necessary materials for learners and provide quality-based learning for them, in addition to effects from teacher shortages. In TL courses, it is also too difficult for teachers to handle individual students [2]. On the other hand, combining technology with education systems (BL) is a more advanced technique that enables the learners to stay motivated and increases their abilities within an interactive learning environment. BL is a learnercentered approach that combines the benefits of both methods (online and traditional) to help learners acquire the necessary skills for their careers and keeps them up-todate with feedback and instruction.

There is a high level of support from a wide range of disciplines for the use of BL. Learning and teaching groups, academic staff, and student groups all agree that BL will benefit institutions; however, this is only true when the strategy is implemented correctly and with the full participation of all required groups [3-8].

Afghanistan is a developing country that has improved its education system over the last several years with the integration of online activities into classroom learning [9-11]. E-learning systems in Afghanistan became popular and widely used starting in 2003 when the Ministry of Information and Communication Technology, with the cooperation of the Ministry of Education (MoE) and Ministry of Higher Education (MoHE), took effective steps towards the implementation and launch of e-learning programs in the country [9]. Finally, after 12 years, in 2015 MoHE successfully developed a comprehensive strategic plan for five years in three major phases to encourage higher institutions to implement and institutionalize e-learning in their educational curriculums.

According to the five-year strategic plan of the MoHE of Afghanistan, the major public universities should integrate some online activities as BL in their educational systems by the end of 2020 [10]. BL is the second stage of the strategic plan from 2017-2018, but universities still lack the required facilities to effectively implement BL well and move the quality of education forward. Additionally, moving from a conventional approach to e-learning is not easy, and many faculty members are concerned about the overwhelming workload and impact of changes needed to establish syllabi and content. In addition, most of the universities in Afghanistan, despite having partial facilities and knowledgeable resources, are not trying to integrate online activities into their education systems. This could be because of a lack of cooperation and effort from top levels and a lack of motivation and understanding of the benefits of e-learning concepts [9].

Since this area of research is mostly unexplored in Afghani higher education, this study will thus investigate and analyze the effectiveness and efficiency of educational types (blended vs. traditional) from six BL and four TL courses. To measure success, we implemented the BL portion in several compulsory credit-based courses for different semesters and compared the overall outcomes with the same courses in the conventional format. We also did a semistructured survey at the end of each semester. 
The experimental results indicated positive outcomes in terms of learners' final performance and could affect motivation and pedagogy in learners' behaviors. Additionally, we have found that the teaching methodology could have a positive impact on the performance of students in a TL course. The rest of the paper is organized as follows: In the coming sections, we report related research (section 2) and quote the examples of the existing studies. In section 3, we describe the study methodology where we emphasize, in particular, the participants and course setting, and follow with data collection and analysis of data. In section 4, we follow with findings followed by discussions in section 5 , and in section 6 , we offer conclusions.

\subsection{Theoretical foundation}

Since the focus area of this research is based on the improvement of teaching and learning through online learning; thus, our main discussion focuses on theories of teaching and learning. a theoretical foundation for teaching and learning will expose and make a clear value and understanding about educational skills. It is by making precise the theoretical principles that we reveal our educational ideals which will have a profound influence on practice. When adopting and replacing the traditional teaching and learning with new, it is essential we think through our educational ideals. Elearning has become the protagonist for change in higher education and brings a revolution to education aspects, but strong needs for stimulus and a purpose [12].

There are several theories related the online learning, more specifically behaviorism, cognitivism, experiential learning, situated learning, constructivism and so on [13], but for this study, the authors used Online Collaborative Learning (OCL) theory [14] which is based on social constructivism and much more suitable for this research. The main goal behind this theory is to introduce learner centered approach to enable the learners to interact, collaborate and practice in related learning. Using skills in the way of practice lets learners to be more confident and formulate new and adaptive concepts. Similarly, OCL theory can help instructors to keep interaction as an active facilitator with learners, as well as challenge the instructors for designing of the target course that leads to positive performance outcomes.

\section{Related Work}

In the last few decades, the position of technology has been quite widely observed in the educational environment and has led to the development and promotion of elearning. The fields mentioned above have been shaped by the intersection of ICTs, teaching, and learning. At service and technology levels, such interest has increased the utilization of a variety of platforms that provide online courses, administer elearning activities, report learners' and lecturers' learning and teaching performances, and inform education-related decisions [15-17]. According to the latest reports, the majority of industries (up to 98\%) around the world will implement e-learning with the purpose of having a digital learning strategy by the end of 2020 [18-19]. Very recently, due to the COVID-19 pandemic, the majority of higher educational institu- 
tions have considered online learning as a part of formal education around the world [20].

$\mathrm{BL}$ is one of the most cited e-learning platforms with a pedagogical and psychological theory background that merges traditional learning with an online learning environment [7]. Currently, e-learning is an emergent trend in higher education as a very significant approach to learning in terms of high learner engagement, student achievement and outcomes, satisfaction, and behavioral change [7, 21].

According to Larson et al. [22], the online and blended learning increased student satisfaction and motivation compared to face-to-face. The authors performed threeway comparison of delivery approaches for an introductory management information systems course. The authors considered the final grade of participants and concluded that the overall final performances of students in face-to-face, blended, and online environments were almost the same, with no positive and significant differences found among delivery modes. However, the students found blended and online learning much more effective than face-to-face. Furthermore, Dziuban et al. [23] reported in their studies that the success of learners mainly related to their previous academic performance, whereas the modality of courses was not much more associated with the success or failure of learners.

Similarly, three separate pharmacotherapy studies indicated the positive integration and importance of face-to-face with online environments. Pierce [24] and Crouch [25] highlighted the performance of students in videos and forum discussions, followed by McLaughlin [7], who found that the academic performance and in-class engagement of learners depended on the content provided before class.

Furthermore, Haron et al. [26] investigated the adoption of BL among Malaysian universities. The authors found that the adoption rate of BL is low, where only 13 percent of the academicians adopted the learning approach. However, the results for the study provided insights on the attitude towards the adoption of BL.

With all current improvement, most higher educational institutions in developing and least developed countries like Afghanistan are still struggling with successful implementation of online learning in their educational environment. Countries that were late adopters of technology still have problems with the reliability of internet access, the gap between rural and urban infrastructure, the quality of services, and so on. According to [27], the ICT development index of countries greatly differs: developed countries ranked 7.52 while developing and least-developed countries were ranked respectively at approximately 4.3 and 2.2. In addition, the individual internetusage penetration for developed countries was estimated at $86.6 \%$, whereas for developing and least-developed countries, it rated at only $47 \%$ and $19.1 \%$, respectively [28]. As Afghanistan proceeds to move forward on modern instruction openings for its citizens, education through cutting-edge strategies and methods such as e-learning must be properly and practically considered. 


\section{$3 \quad$ Methodology}

\subsection{Course development}

One of the major issues in online learning is the way of providing learning materials, sequence the elements of the course, and engage learners with the contents. However, well consideration of the course elements including tools deployed (e.g. forum), the activity put in place for the learners (e.g. taking quizzes, submitting assignments), and learning contents provided (e.g. textbooks, lecture notes) could influence the behavior of learners and instructors to engage in online activities and effectively carry out the specified learning and teaching activities. Therefore, the element of the course should be systematically designed, goal-oriented, and well-panned. To measure success, the Analysis, Design, Development, Implementation, and Evaluation (ADDIE) [29-30] model has been applied for designing of course elements (syllabi) in this research.

In the Analysis phase, the existing course syllabuses are reviewed and the necessary actions have been taken into account with all the subsequent work based on its outcome. Basic actions in this phase include clarification of the instructional problem, the establishment of instructional objectives according to learners' knowledge and skills, and identification of the learning environment as well as evaluation types. In the second stage (Design), the method of learning and teaching was evaluated and the necessary measures were considered. Tasks in the Design phase cover the sequence of course elements such as schedule and task assignment, evaluation methods (summative and formative), tool design, group forming among students, the arrangement of activities, and pedagogical strategy.

In the third phase (Development), the contents of pedagogy were constructed and developed. In this phase, we adopted the Moodle platform as a part of a blended learning environment. Both types of courses (BL and TL) were organized with several online and traditional activities. In the fourth stage (Implementation), the actual instructions and delivery of learning experiences were done in the second semester of the 2018 academic year and through the 2019 academic year. Eventually in the last phase (Evaluation), all the courses were evaluated in the form of comments during the course and through end-of-course surveys by students.

\subsection{Participants and course setting}

The e-learning courses were developed by lecturers from the first semester of the 2018 academic year during April and August and implemented in the second semester of the 2018 academic year and through the 2019 academic year. In this analysis, six BL $(n=286)$ and four TL $(n=239)$ classes of sophomore-level, junior-level, and seniorlevel subjects from several departments were taken into consideration. All courses were compulsory-credit courses taught by the computer science faculty of Kabul Polytechnic University. Among these BL students, 36\% ( $\mathrm{n}=102)$ were female and 
$64 \%(n=184)$ were male. In contrast, $35 \%(n=82)$ of the TL students were female and $65 \%(n=151)$ were male.

In this study, we covered different courses according to the class level and department. The class levels comprise sophomore-level (46\%), junior-level (32\%), and senior-level (22\%) students. Similarly, three different departments of computer science faculty (i) information technology (IT), (ii) computer engineering (CE), and (iii) computing and information science (CS) are included in the survey. To better understand the effectiveness and impact of BL courses in the academic performance and motivation of students, the implementation of BL into these courses was evaluated in two different ways. For the first step, three BL courses and two TL courses were selected for the sophomore and junior-level classes. In this step, IT-1 joined BL, whereas $\mathrm{CS}-1^{1}$ joined TL for the system analysis and design (SAD) course. The CS-2 and CE-2 departments joined BL while IT-2 joined TL for the operating system (OPS) course, respectively.

In contrast, in the next semester, two BL courses and a TL course were considered in the context of data structure and algorithm (DSA) and mobile application development (MAD) courses for the same departmental students. This time, IT-1 and CS-1 were joined in BL, while CE-1 joined TL for the DSA. IT-2 joined the blended, whereas CS-2 joined TL for the MAD course. Table 1 represents the summary of the online and traditional activities mean score for both BL and TL students.

Table 1. Average scores of 4 subjects

\begin{tabular}{|l|l|c|c|c|c|}
\hline \multicolumn{1}{|c|}{ Activities } & \multicolumn{1}{c|}{ Score (Mean)/ 100 } & SAD & OPS & DSA & MAD \\
\hline Online & Assignments/ Quizzes & 79.8 & 70.4 & 59.5 & 81.8 \\
\hline Traditional & Assignments/ Quizzes & 69.3 & 61.6 & 78.4 & 70.5 \\
\hline
\end{tabular}

The BL courses were organized with several online activities (such as taking weekly quizzes, submitting assignments, participating in forum discussions, and a mid-term examination, with a mid-term exception for MAD only), whereas in the TL courses, the lecturers provided almost the same weekly activities (with optional quizzes) in the traditional manner to students. Additionally, both classes of BL and TL consisted of some on-campus activities, such as mid-term examinations, final examinations, after assignment reviews (debriefing assignments), and classroom lectures. Table 2 shows the summary of online and in-class activities for BL and TL, respectively.

\footnotetext{
${ }^{1}$ SAD course conducted under the name of System Planning and Analysis (SPA) for CS-1 in the former curriculum (There is no difference between SAD and SPA syllabi).
} 
Paper-Improving Academic Performance Through Blended Learning: The Case of Afghan Higher...

Table 2. Summary of online and in-class activities for all courses

\begin{tabular}{|l|l|l|}
\hline \multicolumn{2}{|c|}{ BL Courses } & \multicolumn{1}{c|}{ TL Courses } \\
\hline Online Activities & In-class Activities & In-class Activities \\
\hline Assignment/ Quizzes & In-class Discussions & Assignments \\
\hline $\begin{array}{l}\text { Mid-term examination (excep- } \\
\text { tional for MAD only) }\end{array}$ & $\begin{array}{l}\text { Assignments Debriefing + Class } \\
\text { Lectures }\end{array}$ & Assignments Debriefing + Class \\
\hline Forum Discussions & Mid-term Examination & Lectures In-class Discussions \\
\hline & Final Examination & Mid-term and Final Examinations \\
\hline
\end{tabular}

All on-campus and online student activities contributed to the final score, and the minimum requirement to earn the credit was to obtain 55 points out of 100 points for each subject.

\subsection{Analysis method and tools}

This study obtained qualitative information to evaluate the effectiveness of educational type (blended vs. traditional) on learners' academic performance and to explore the concerns, challenges, and feedback regarding each. In this study, a questionnaire consisting of 43 items with three sections (demographic, noncognitive towards BL and TL courses, and open-ended in order to allow participants to present their comments and suggestions) was developed for use as a data collection tool. The sample of questionnaires for both $\mathrm{BL}$ and $\mathrm{TL}$ can be accessed through https://pydio.hicc.cs.kumamoto-u.ac.jp/public/f130b2. During the study, 401 valid questionnaires were obtained by the respondents out of 507 questionnaires, which include $68 \% \mathrm{BL}$ and $32 \%$ TL courses. Among students, $37 \%(\mathrm{n}=148)$ were female and $63 \%(\mathrm{n}=253)$ were male. Our qualitative data mainly consists of five types of selective answers, namely, "Strongly Agree," "Agree," "Neutral," "Disagree," and "Strongly Disagree." Responses from students were measured using a 5-point Likert-type scale that ranges between 5 to 1 for "Strongly Agree" to "Strongly Disagree," accordingly. The analysis tool was designed in $\mathrm{R}$ and Python programming languages in order to enable us to extract any type of analytical and statistical information we required. We have used descriptive statistics (mean, $M$; and standard deviation, SD). Welch's t-test was also used to compare BL courses with TL courses to determine the differences in success and failure levels in both courses. Likewise, the Pearson correlation coefficient, along with an ordinary least square (OLS) regression, was used to indicate the relationship between the final score and the BL and TL activities, respectively. 


\section{$4 \quad$ Findings}

\subsection{Pearson coefficient of the correlation analysis results}

According to the Pearson coefficient of the correlation analysis shown in Fig. 1, there was a positive relationship between the final score and the online activities for all the BL courses $\left(r=0.83, p<0.01^{2}\right)$, while the correlation between the final score for all the TL courses was moderately positive $(r=0.62, p<0.01)$ (Fig. 2). Likewise, the relationship between the GPA earned for the semester and the final score of the student was evident in both BL and TL courses. The correlation between semester GPA and final score in TL courses was moderately positive $(r=0.49, \mathrm{p}<0.01)$, whereas a strong positive correlation exists between the semester GPA and final score in BL courses $(r=0.65, p<0.01)$. This result was consistent with the findings of [31], who achieved similar results between online and face-to-face enrollments. Conversely, a very weak positive relationship was achieved between the Kankor ${ }^{3}$ score and the final score of students in BL courses $(r=0.16, p<0.01)$, whereas the relationship between the Kankor score and the final score of students in TL was negative $(r=-$ $0.33, \mathrm{p}<0.01)$. Fig. 1 illustrated the correlation coefficient analysis results for $\mathrm{BL}$ and Fig. 2 for TL courses.

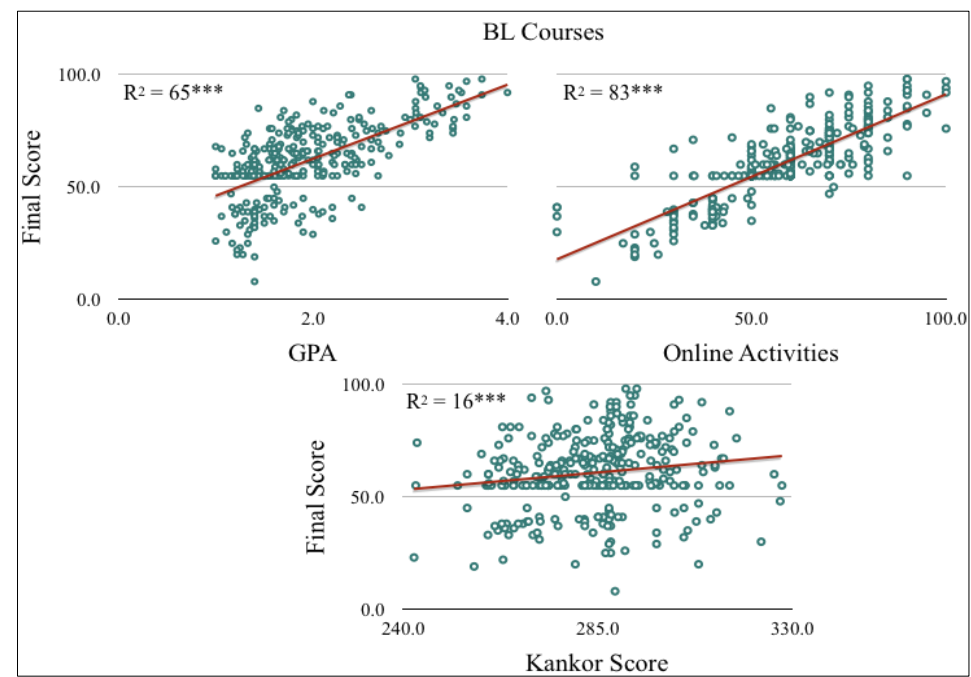

Fig. 1. Correlation coefficient analysis results for BL courses

\footnotetext{
${ }^{2}$ A P-value $<.05$ was considered statistically significant.

${ }^{3}$ Kankor is a proficiency university entrance exam in Afghanistan, taken by school graduates in order to be admitted into higher institutions. The maximum score for the Kankor exam is 360 .
} 


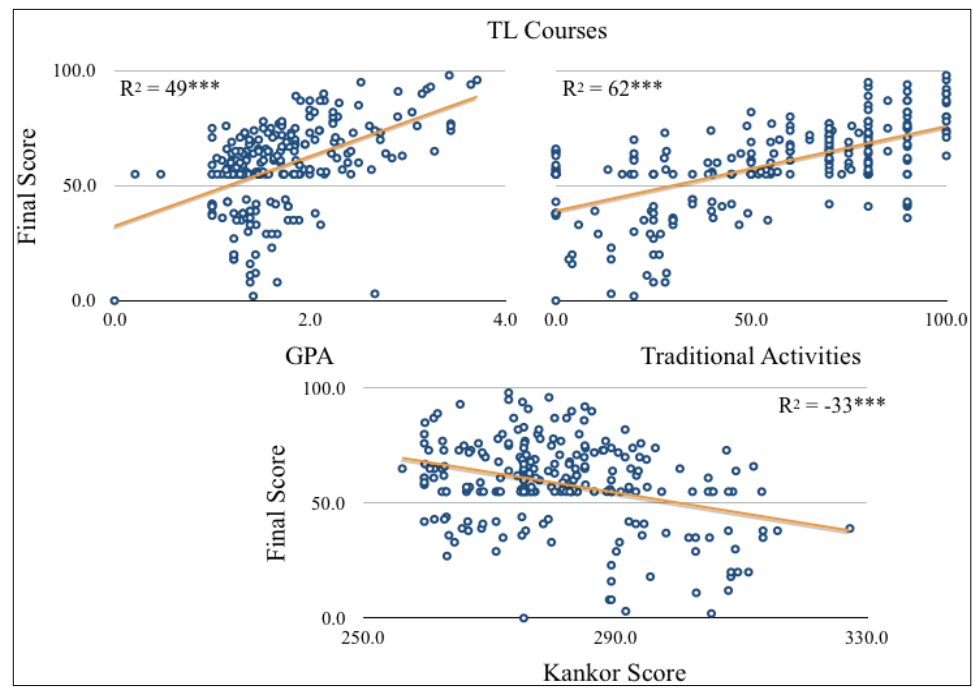

Fig. 2. Correlation coefficient analysis results for TL courses

\subsection{Ordinary least square analysis results}

Similar results were obtained from analysis with ordinary least square (OLS) regression. Hence, this again corroborated the hypothesis that a significant difference existed between the average educational type (BL and TL), and online activities seemed to have a positive effect on the final outcome of students. Tables 3 and 4 indicate the summary results of OLS regression for both BL and TL courses.

Considering the results obtained, it seems that there was some variability in terms of positive and significant correlation in the final score between BL and TL courses. In BL courses, the online activities and semester GPA had high positive correlations with the final achievement of students, whereas a weak relationship existed between the final score and the Kankor score. In contrast, the traditional activities and semester GPA were not very associated with the final score of students in TL courses. Similarly, the relationship between the final score and the Kankor score was negative for the TL courses. This variability in terms of correlation could indicate differences in terms of the engagement of students towards online activities, the diversity of the type of activity which reflects how students have prioritized the activities performed in both environments, and other factors (pedagogical and psychological) in relation to online activities. Therefore, we conclude that the BL approach used for BL courses was generally well received by the students compared to TL courses.

However, the TL students for the DSA course performed better than the BL students. The completion rates differ greatly ( $\mathrm{p}<.001)$, with $78.4 \%$ of the TL students completing the traditional activities compared to the BL students (59.5\%) (Table 1). This is because of the differences in the courses setup (since both groups of students taught by two different lectures), followed by differences in students' efforts to solve problems more efficiently and comfortably in the conventional manner (without the 
constraints of time and place for assignment submission), as well as and teaching methodology could be the other possible reason that totally effect the performance of the traditional DSA course performed better compared to the blended one. These findings not only highlighted the importance of integrating online activities with classroom learning but also the importance of teaching methodology and the convenience of students and their classroom involvement in regards to the traditional way. Similarly, this also proves that the traditional way of teaching and learning could also be an appropriate way to achieve course objectives.

Table 3. Summary of OLS regression results for BL courses

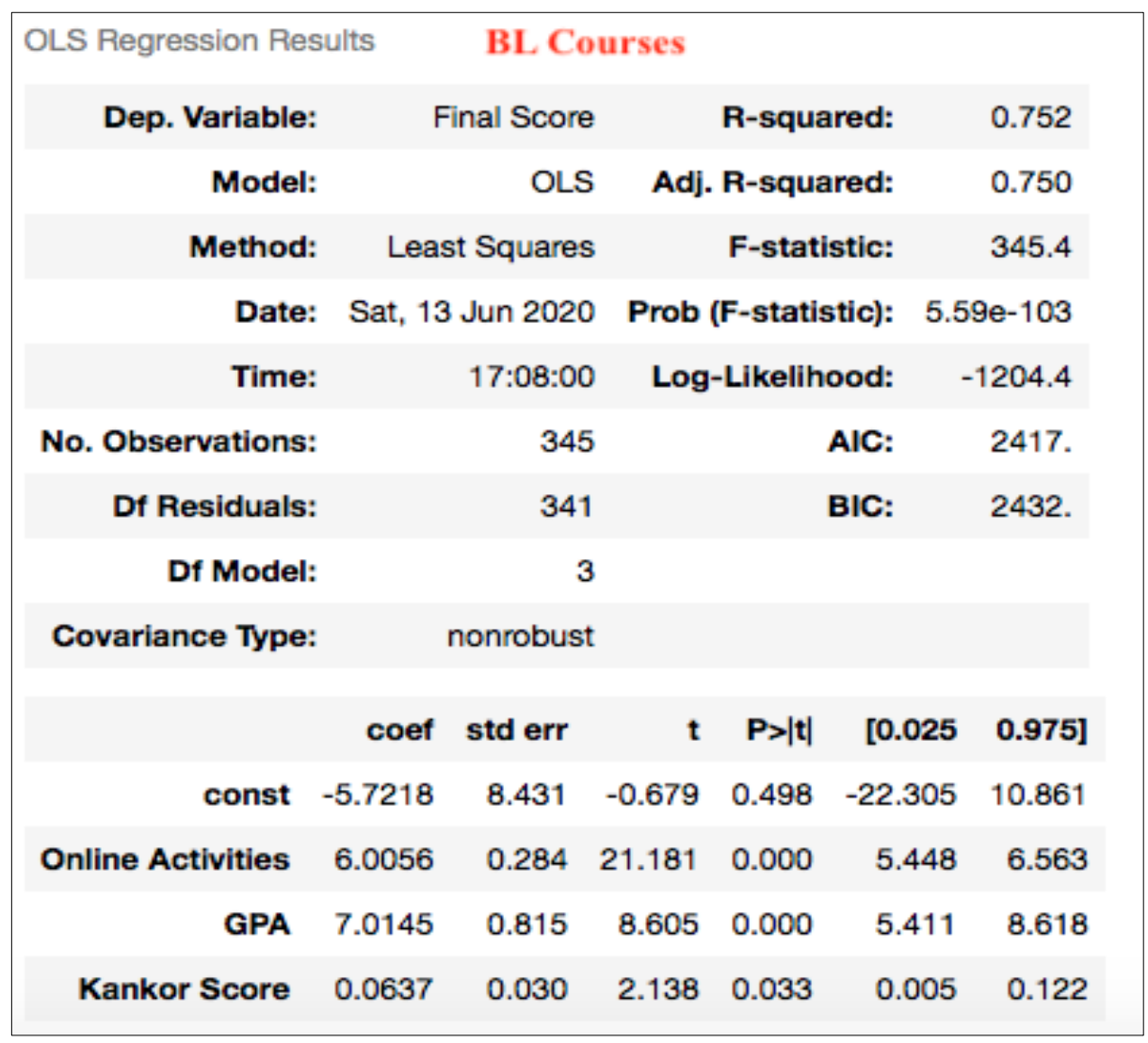


Table 4. Summary of OLS regression results for TL courses

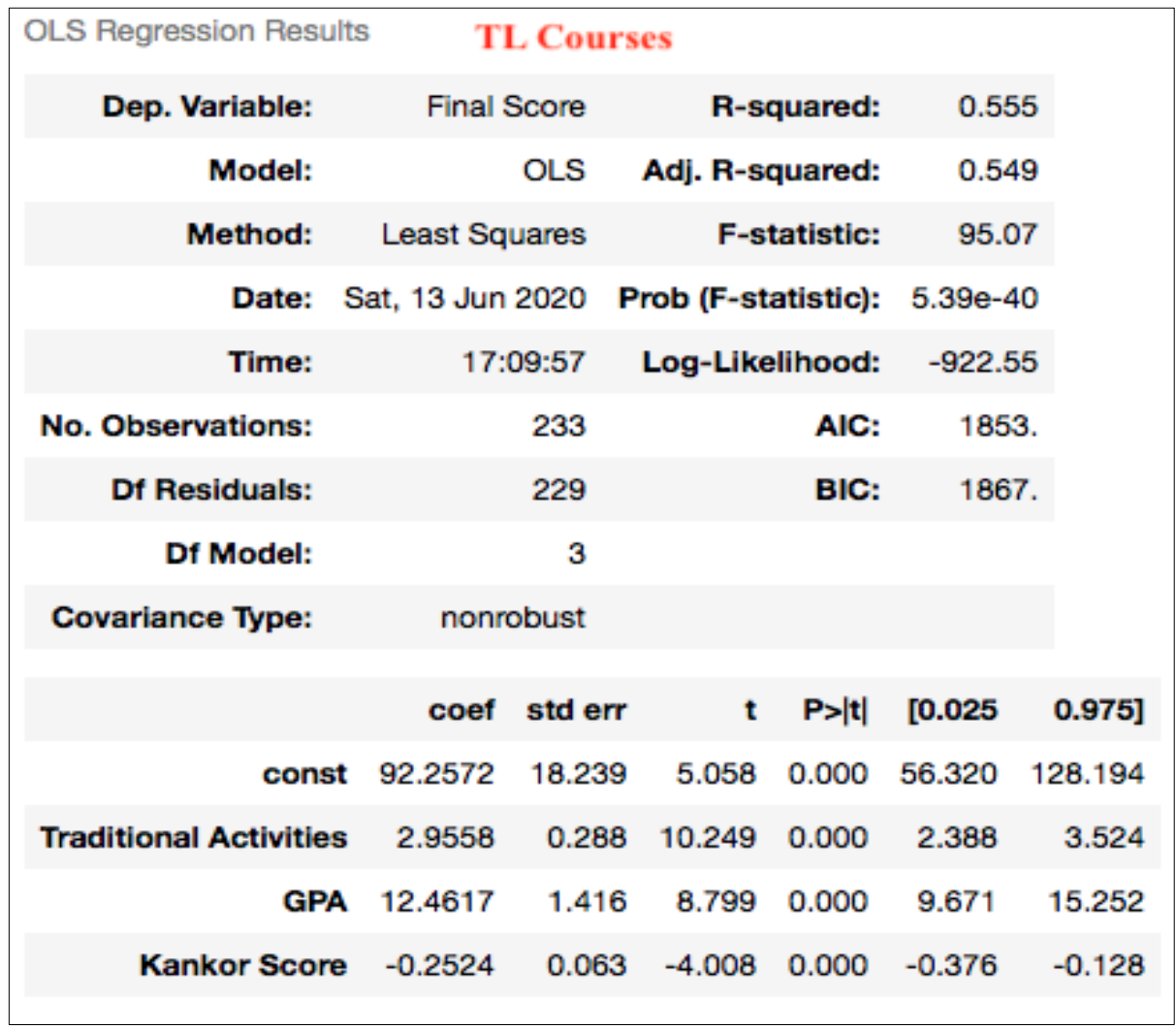

Likewise, from an analysis of the OLS regression, a positive relationship existed between the defined independent variables and target variable $(\mathrm{F}=345.4, \mathrm{p}<.001)$ with an R-squared of 0.75 for BL students, whereas the same relationship exists for TL students $(\mathrm{F}=95.1, \mathrm{p}<.001)$ with a comparable R-squared of 0.55 . Therefore, we can assume that the engagement of students in online activities seemed to have a considerable effect on their final outcomes and knowledge retention, resulting in the achievement of course objectives.

To sum up, the improved scores on the BL courses indicated that the online activities contributed to students' final achievements and understanding and provided a better way for students to achieve their goals and increase their knowledge. However, the TL environment has its own efficiency, and with the integration of online activities, it adds to its effectiveness and can be more focused on the motivation of students.

\subsection{Descriptive analysis results}

As mentioned above, we also obtained qualitative information for this study. Based on descriptive analysis results, we found that the BL activities were much more asso- 
ciated with the interest of students and that students in BL courses achieved better results compared to those in the TL courses. Table 5 explains the results of descriptive statistics for both the BL and TL students' perceptions.

Table 5. Result of descriptive statistics for both the BL and TL students' perceptions

\begin{tabular}{|c|c|c|c|c|c|c|}
\hline \multirow{3}{*}{ Item } & \multirow{3}{*}{ Description } & \multicolumn{4}{|c|}{ Responses } & \multirow{3}{*}{ P-value } \\
\hline & & \multicolumn{2}{|c|}{$B L$} & \multicolumn{2}{|c|}{$T L$} & \\
\hline & & $M$ & $S D$ & $S D$ & $S D$ & \\
\hline 1 & Effectiveness of Online/In-class materials & 4.1 & 1.0 & 3.6 & 1.1 & $\leq 0.001$ \\
\hline 2 & Effectiveness of Online/In-class Quizzes & 4.0 & 1.1 & 3.6 & 1.1 & $\leq 0.001$ \\
\hline 3 & Effectiveness of Online/In-class Assignments & 4.0 & 1.1 & 3.5 & 1.1 & $\leq 0.001$ \\
\hline 4 & Effectiveness of Online Forum Discussion/In-class interaction & 3.0 & 1.2 & 3.5 & 1.2 & $\leq 0.001$ \\
\hline 5 & $\begin{array}{l}\text { I prefer using a computer and collaborating with other people } \\
\text { than working alone/using a textbook and working alone }\end{array}$ & 4.0 & 1.1 & 2.6 & 1.3 & $\leq 0.001$ \\
\hline 6 & Daily access to the internet & 3.0 & 1.2 & 3.3 & 1.3 & $\leq 0.1$ \\
\hline 7 & $\begin{array}{l}\text { Online/Traditional courses are engaging me more to learn } \\
\text { better. }\end{array}$ & 4.0 & 1.1 & 2.6 & 1.2 & $\leq 0.001$ \\
\hline 8 & $\begin{array}{l}\text { I am willing to make time to use online activities that affect } \\
\text { my academic performance in my learning. }\end{array}$ & 4.2 & 1.0 & 4.3 & 0.9 & 0.1 \\
\hline 9 & $\begin{array}{l}\text { Overall, how do you rate your key success indicators (motiva- } \\
\text { tion, attitudes, pedagogy, and retention) towards Blend- } \\
\text { ed/Traditional activities }\end{array}$ & 4.1 & 0.9 & 2.6 & 1.3 & $\leq 0.001$ \\
\hline
\end{tabular}

In Table 5, the mean $(M)$, standard deviation $(S D)$, and $p$-value are explained in detail for each item.

Generally, we found that BL activities could influence the academic performance of learners compared to TL activities at highly significant value, specifically for items $1-3,5,7$, and 9 . There were statistically significant $(p<.001)$ relationships between students' perceptions of online activities and engagement towards the BL environment. This result aligns with the findings of [22, 32-33], who found that blended and online courses were much more often associated with student satisfaction.

In contrast, the online forum discussion (item 4) is not substantially related to the interest of students compared to in-class interaction. This result is in contrast with Larson [22] who found that discussion in blended and online formats was entirely related to student satisfaction. Similarly, item 6, "lack of daily access to the internet," had a wholly negative effect on academic performance. From both groups' perspective, respondents felt that the university lacked enough facilities (lack of daily internet access, computer lab, IT infrastructure maintenance), and capacity (despite the rapid expansion of students) to accommodate the demand of students. However, according to item 8 both BL and TL respondents showed interest and motivation in improving their performances when using online activities.

Fig. 3 indicates the students' perceptions towards e-learning satisfaction compared to e-learning facilities, computer access, and internet access in relation to learning objectives. 


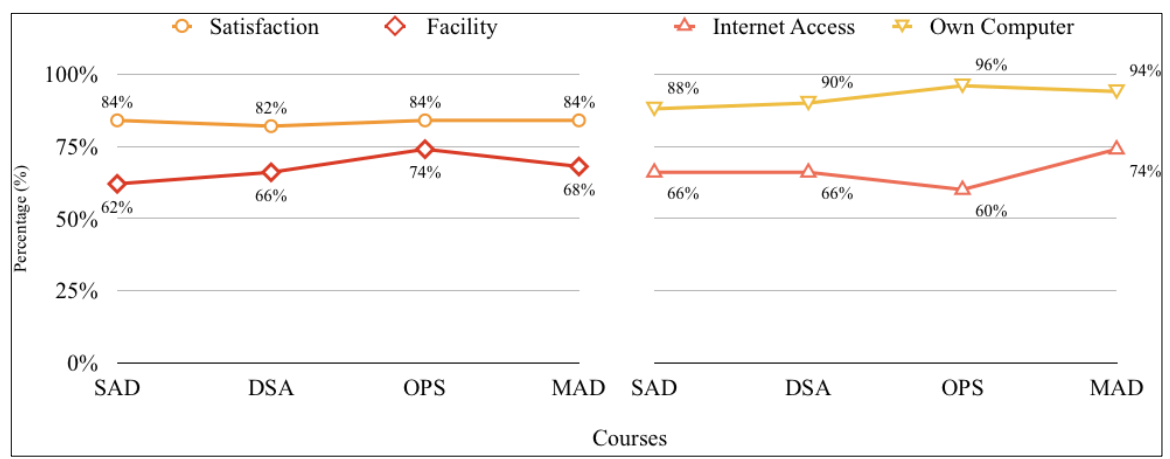

Fig. 3. Students' perceptions towards e-learning satisfaction compared to facilities, computer, and internet access for all courses

As illustrated in the figure, the percentage of students' satisfaction towards elearning activities hovers above $80 \%$ for all courses, with a minor drop for DSA.

While the percentage shown in the figure was adequately high, it indicates that there remains a percentage of dissatisfaction in achieving learning objectives. This could be attributed to a lack of consideration regarding students' abilities to use technology and have access to content and online activities outside the classroom. According to Stockwell et.al [34], technology itself is unlikely to engender motivation or autonomous behavior in many learners unless the environment can be arranged with a sufficient balance of motivation and skill. In this vein, the role of the lecturer as a motivator and supporter is vital and has an efficient impact on learning objectives.

\section{Discussion}

The study results revealed significant $(\mathrm{p}<.001)$ differences in students' activities in BL and activities in TL. Additionally, according to the Pearson coefficient of correlation results, a strong positive relationship $(\mathrm{r}=0.83, \mathrm{p}<0.01)$ exists between the final score and the online activities for the BL courses, while a small to medium relationship ( $\mathrm{r}=0.62, \mathrm{p}<0.01$ ) was associated with TL courses. Similarly, according to OLS regression results, there was a high positive relationship existing between the final score of students and their online activities, GPA, and Kankor score compared to those of the TL courses. The study results also indicated that both BL and TL students were ready to engage in online activities since their perceptions showed that online activities could impact on their final success compared to TL activities. Thus, this information could be valuable for educational parities in order to examine the factors that influence students' performance, and it could pave the way for institutionalization of BL throughout the country. Furthermore, these findings could present a great opportunity for lecturers to find motivation in preparing and sustaining online activities (computer-mediated instructional material), which will require a great deal of effort but can also be easily modified and brought up to date in subsequent years. 
Likewise, the study results indicated that there was a significant difference between BL and TL students' perceptions. The average response scores from items (1-9) of BL and TL students were not equal from the mean estimates, we concluded that the TL average score was lower than that of the BL students. Therefore, there is a dire need for the university to provide enough facilities for students to use for online activities and to accommodate their demands, as well as to facilitate classrooms that enable lecturers to implement the teaching-learning processes and instructional strategies in an appropriate manner. In addition, lecturers need to facilitate the environment much more effective by monitoring students' online activities and providing timely feedback. This approach can motivate learners to engage and be responsible in their activities in a more sustained manner. Therefore, faculty members and students should be mindful of using technology in an appropriate manner, which in turn can lead to a results-oriented teaching and learning environment.

The overall findings suggested that the Ministry of Higher Education should make clear goals and strategies for the implementation of e-learning, governance of the national e-learning plan and syllabus, enhancement of lecturer training, enhancement of required facilities, and for the provision of adequate infrastructure for universities. In addition, it is strongly recommended that lecturers should include e-learning in their teaching methodology and place a greater focus on formative assessments as opposed to summative.

\section{Conclusion}

The overall evaluation demonstrated that BL courses play a major role in learners' academic performances and could effectively affect motivation and pedagogy in learners' behaviors. In addition, the experimental results indicated that the learners' class engagement could have a positive relationship with the teaching methodology that makes differences in students' efforts to solve problems more efficiently, more comfortably, and in a way more likely to achieve course objectives.

Similarly, the overall findings revealed that the university needs to focus more on online activities, provide enough facilities, and encourage lecturers and students to use e-learning in their teaching and studying. There is also a need for lecturers to improve course materials. In addition, it is strongly recommended for lecturers to consider the course evaluation system properly and devote a substantial percentage of the overall score to student activities, especially in online activities.

In conclusion, the experimental results demonstrated a positive outcome for the final academic performance of students and pointed to the potential of BL activities regarding the success of learners and serving their academic needs in a significant way. From these findings, a forum can also be provided that enables academies to collaborate on ways to overcome concerns and challenges that they identify.

Further research will focus on analyzing the other major theoretical background that informs more the study. Similarly, for future work, we intend to review the aspects of BL such as challenges of BL implementation in the classrooms as well as, 
aspects of TL including a relevant theory that could be used to frame a comprehensive result.

\section{$7 \quad$ Acknowledgement}

We are very grateful to the computer science faculty members, senior teaching assistant Ahmad Nawid Mustafazada, Niaz Mohammad Ramaki, Sohail Mukhtar, and Aman Sultani for their cooperation in the collection of data at KPU. The authors would also like to thank all of the students for taking part in our survey. Finally, the authors would like to thank Sabahuddin Sokout for his assistance in proofreading. This manuscript has been technically proofread by Elsevier Language Editing Services.

Funding Part of this work was supported by the JSPS KAKENHI Grant-in-Aid for Scientific Research 19K1225100 and 15H02795.

\section{$8 \quad$ References}

[1] Sokout. H and Paracha. S. (2015). "Intelligent tutoring system: Approaches, researches and e-learning solution," 2015 IEEE 8th International Workshop on Computational Intelligence and Applications, Hiroshima, pp. 53-58 (2015). https://doi.org/10.1109/iwcia.2015.7449462

[2] Sessink, O., Beeftink, H., Tramper, J., \& Hartog, R. (2007). "A Lecturer-Friendly Adaptive Tutoring System," Journal of Interactive Learning Research, 533-554.

[3] Bliuc. A, Ellis. R, Goodyear. P and Piggott. L. (2011). "A blended learning Approach to teaching foreign policy: Student experiences of learning through face-to-face and online discussion and their relationship to academic performance," Computers \& Education, vol. 56, no. 3, pp. 856-864. https://doi.org/10.1016/j.compedu.2010.10.027

[4] Li L, Tang H. (2012). "In Teaching physics with blended learning," Proceedings of World Conference on Educational Multimedia, Hypermedia and Telecommunications.

[5] Li. L and Tony Tang. H. (2017). "Teaching Physics with Blended Learning," Journal of Modern Education Review, vol. 7, no. 4, pp. 231-241.

[6] Kapur, R. (2018). "Factors Influencing the Students' Academic Performance in Secondary Schools in India," India.

[7] McLaughlin JE, Griffin LM, Esserman DA, et al. (2013). "Pharmacy student engagement, performance, and perception in a flipped satellite classroom," Am J Pharm Educ. 77(9): Article 196.

[8] Picciano AG, Dziuban CD, Graham CR. (2014). "Blended Learning: Research Perspectives," Vol. 2. New York, NY: Routledge.

[9] Sokout, H and Usagawa, T. (2018). "Analyzing the Current Situation of E-learning at Kabul Polytechnic University," In Proceedings of the 2nd International Conference on Education and Multimedia Technology, Okinawa, July 2-4. https://doi.org/10.1145 13206129.3239428

[10] Sokout. H and Usagawa. T. (2019). "E-learning readiness toward the quality of teaching and learning: A preliminary study of 6 major Afghan public universities," in the 14th International Student Conference on Advanced Science and Technology, pp. 194-195 (2019). 
[11] H. Sokout, T. Usagawa and S. Mukhtar, (2020). "Learning Analytics: Analyzing Various Aspects of Learners' Performance in Blended Courses. The Case of Kabul Polytechnic University, Afghanistan", International Journal of Emerging Technologies in Learning (iJET). vol. 15, no. 12, p. 168. doi: 10.3991/ijet.v15i12.13473.

[12] Garrison. D, Kanuka. H. (2004). "Blended learning: Uncovering its transformative potential in higher education," The Internet and Higher Education, 7:95-105. https://doi.org/10. 1016/j.iheduc.2004.02.001

[13] Sokout. H, Paracha. S. (2014). "The Prospects of e-Kankor Exam Prep System in Afghanistan," In the Asian Ctheerence on Technology in the Classroom 2014, pp 188-198.

[14] Demuyakor. J. (2020). "Coronavirus (COVID-19) and Online Learning in Higher Institutions of Education," Online Journal of Communication and Media Technologies. doi: $10.29333 / \mathrm{ojcmt} / 8286$.

[15] Muljana, P. S. \& Luo, T. (2019). "Factors contributing to student retention in online learning and recommended strategies for improvement: A systematic literature review," Journal of Information Technology Education: Research, 19-57. https://doi.org/10.28945/4182

[16] Safsouf, Y., Mansouri, K., \& Poirier, F. (2020). "An analysis to understand the online learners' success in public higher education in Morocco," Journal of Information Technology Education: Research, 19, 87- 112. https://doi.org/10.28945/4518

[17] Sclater. N. (2017). "Learning Analytics Explained," Florence: Taylor and Francis, pp.3543 (2017).

[18] Keegan. L. (2019). “Online Learning Statistics 2020 (All You Need To Know!), 'SkillScouter. Available: https://skillscouter.com/online-learning-statistics

[19] Bose. S. (2017). " $98 \%$ of All Companies Plan to Use E-Learning by 2020 with Opportunities for Small Biz - Small Business Trends, Small Business Trends," Available: https://smallbiztrends.com/2017/12/2018-e-learning-trends.html

[20] UNESCO. (2020). "COVID-19 educational disruption and response," Retrieved from. https://en.unesco.org/covid19/educationresponse

[21] Pandey, A. (2020). "eLearning Trends in 2020: Featuring Tips on How You Can Leverage Them for Learning, Performance Gain, and Behavioral Change," [Ebook], pp. 21-68.

[22] Larson. D and Sung. C. (2009). "Comparing student performance: online versus blended versus face-to-face," Journal of Asynchronous Learning Networks, vol. 13, no. 1, pp.3142. https://doi.org/10.24059/olj.v13i1.1675

[23] Dziuban. C and Moskal. P. (2011). "A course is a course is a course: Factor invariance in student evaluation of online, blended and face-to-face learning environments," Internet and Higher Education, vol. 14, pp. 236-241. https://doi.org/10.1016/j.iheduc.2011.05.003

[24] Pierce. R and Fox. J. (2012). "Vodcasts and Active-Learning Exercises in a Flipped Classroom Model of a Renal Pharmacotherapy Module," American Journal of Pharmaceutical Education, vol. 76, no. 10, p. 196 (2012). https://doi.org/10.5688/ajpe7610196

[25] Crouch. M. (2009). "An Advanced Cardiovascular Pharmacotherapy Course Blending Online and Face-to-Face Instruction," American Journal of Pharmaceutical Education, vol. 73, no. 3, p. 51. https://doi.org/10.5688/aj730351

[26] Bax. S. (2003). "CALL-past, present and future. System," 31:13-28. https://doi.org/10.1016/s0346-251x(02)00071-4

[27] ITU. (2017). “Global ICT Development Index," ITU, Itu.int, 2020. Available: https://www.itu.int/net4/ITU-D/idi/2017/index.html\#idi2017 comparison-tab. https://doi.org/10.23919/itu-wt.2017.8247006

[28] ITU. (2019). Measuring digital development Facts and figures, ITU, Geneva. 
[29] Kurt, S. (2018). “ADDIE Model: Instructional Design - Educational Technology. Educational Technology," Retrieved 15 October 2020, from. https://educationaltechnology.net/the-addie-model-instructional-design/

[30] Culatta, R. (2020). "ADDIE Model - InstructionalDesign.org. InstructionalDesign.org," Retrieved 15 October 2020, from: https://www.instructionaldesign.org/models laddie/\#: :text=The\%20ADDIE\%20model\%20is\%20the,training\%20and\%20performance \%20support\%20tools

[31] Berry. L. (2017). "Using learning analytics to predict academic success in online and faceto-face learning environments," Ph.D, Boise State University. https://doi.org/10.18122/ $\underline{\mathrm{b} 2 \mathrm{ct} 4 \mathrm{t}}$

[32] Ashby. J, Sadera. W and McNary. S. (2011). "Comparing student success between developmental math courses offered online, blended, and face-to-face," Journal of Interactive Online Learning, vol. 10, no. 3, pp. 128-140.

[33] Martínez. P. J, Aguilar. F. J and Ortiz. M. (2020). "Transitioning from Face-to-Face to Blended and Full Online Learning Engineering Master's Program," in IEEE Transactions on Education, vol. 63, no. 1, pp. 2-9. https://doi.org/10.1109/te.2019.2925320

[34] G. Stockwell and H. Reinders. (2019). "Technology, Motivation and Autonomy, and Teacher Psychology in Language Learning: Exploring the Myths and Possibilities", Annual Review of Applied Linguistics, vol. 39, pp. 40-51. Available: https://doi.org/10.1017/ $\underline{\mathrm{s} 0267190519000084}$

\section{Authors}

Hamidullah Sokout is a lecturer at (Faculty of Computer Science) Kabul Polytechnic University. He has also worked as a member of quality assurance and accreditation at the Ministry of Higher Education of Afghanistan until 2017. He earned his master degree in Information Systems from Kobe Institute of Computing in 2015. He is currently a Ph.D. student in the Graduate School of Science and Technology, Kumamoto University, Japan. His research interest includes E-learning, Learning Analytics and adaptive learning.

Tsuyoshi Usagawa joined Kumamoto University in 1983 right after he received an M.E. degree from Tohoku University. In 1988, he received a Dr. Eng. from Tohoku University. Since 2004 he has been a professor, and he is a member of the IEEE, ASA, ASJ, INCE/J, JSET, and JSAI. He is interested in e-learning contents and systems, and acoustic signal processing. tuie@cs.kumamoto-u.ac.jp

Article submitted 2020-12-25. Resubmitted 2021-01-28. Final acceptance 2021-01-30. Final version published as submitted by the authors. 